\begin{tabular}{|c|c|c|}
\hline & ORIGINAL RESEARCH PAPER & Biochemistry \\
\hline RIPL & $\begin{array}{l}\text { A RARE CASE OF SECONDARY FAHR'S } \\
\text { SYNDROIME AS A SEQUELAE OF POST } \\
\text { THYROIDECTOIMY HYPOPARATHYROIDISM } \\
\text { REPORTED TO A TERTIARY CARE HOSPITAL. }\end{array}$ & KEYWORD: \\
\hline
\end{tabular}

Dr. Abdul Rahim Rehan*

\section{Miss. Sharanya}

Sai Manga

\section{Dr. Sujatha Rani}

2nd year MD Biochemistry Postgraduate, Osmania Medical College, Hyderabad,Telangana,India. *Corresponding Author

Medical Student,Shadan Medical College, Hyderabad, Telangana, India.

Professor and head of the Department of Biochemistry, Osmania Medical College, Hyderabad,Telangana,India.

\footnotetext{
OBJECTIVES: To emphasize the presentation, etiopathogenesis and various diagnostic findings in a case of secondary Fahr's syndrome.

METHODOLOGY: A 35 year old female who had undergone total thyroidectomy 9 yrs ago due to papillary carcinoma of thyroid, presented with seizures and weakness in both lower limbs, secondary to hypoparathyroidism. Non contrast computed tomography of brain showed bilateral calcification in basal ganglia, centrum semiovale and cerebellar hemisphere.

RESULT: The patient was diagnosed with Fahr's syndrome as a sequelae of post thyroidectomy hypoparathyroidsm. CONCLUSION: We recommend the follow up of blood calcium, phosphorus , PTH levels every 3 months during lst year after Thyroidectomy and every 6 months subsequently, for the long term follow up of post -thyroidectomy patients along with routine CT scanning.
}

\section{BACKGROUND:}

Idiopathic basal ganglia calcification also known as Fahr's disease is a rare neurological disorder having very low prevalence of $(<1$ per million population) but is considered under-reported (1).The disease is characterized by bilateral symmetrical calcium deposition in areas of the brain associated with movement control like the basal ganglia and adjacent parenchyma such as the dentate nuclei, putamen, thalami, cerebral cortex, subcortical white matter, hippocampus and cerebellum (1). The term Fahr's disease is used when primary familial brain calcification is present, and the term Fahr's syndrome is used for secondary causes due to underlying calcium and phosphate disorders. (2). In this case study, we report a case of Fahr's syndrome in a patient due to post thyroidectomy secondary hypoparathyroidism. The aim of this case report is to emphasize the importance of routine biochemical and radiological checkups and long term followup of post thyroidectomy patients.

\section{CASE PRESENTATION:}

A 35 year old female presented to our tertiary care hospital with chief complaints of seizures which were intermittent since $2 \mathrm{hrs}$, with each episode lasting for 5minutes, in the month of october 2019. The seizures are generalized tonic clonic type, associated with tongue bite and involuntary micturition followed by postictal confusion. The symptoms had begun insediously with abnormal uncontrolled movements starting in both the lower limbs progressing to generalized tonic clonic seizures.History of similar complaints since past 4 years for which she was prescribed anti-epileptics. Surgical history includes total thyroidectomy 9 years back due to underlying papillary carcinoma of thyroid.No significant family history of similar complaints or any other neurological disorder.Her clinical course was characterized by progressive deterioration with seizure activity not controlled by medications. Biochemical evaluation and CT Brain was done. During the course the patient aspirated and developed acute respiratory distress syndrome (ARDS), followed by refractory shock leading to death.

The Biochemical Findings Are Given In Table 1.

A non-contrast CT scan revealed massive calcifications involving the basal ganglia, centrum semi ovale and |www.worldwidejournals.com

cerebellar hemisphere (Fig. l) and (Fig.2)
\begin{tabular}{|c|c|}
\hline Biochemical tests & Patient's value \\
\hline GRBS $(70-140 \mathrm{mg} / \mathrm{dl})$ & $110 \mathrm{mg} / \mathrm{dl}$ \\
\hline Urea $(15-40 \mathrm{mg} / \mathrm{dl})$ & $35 \mathrm{mg} / \mathrm{dl}$ \\
\hline Creatinine $(0.6-1.4 \mathrm{mg} / \mathrm{dl})$ & $1.0 \mathrm{mg} / \mathrm{dl}$ \\
\hline T3 $(0.87-1.78 \mathrm{ng} / \mathrm{ml})$ & $0.31 \mathrm{ng} / \mathrm{ml}$ \\
\hline T4 $(6.09-12.23 \mu \mathrm{g} / \mathrm{dl})$ & $3.6 \mu \mathrm{gg} / \mathrm{dl}$ \\
\hline TSH $(0.34-5.60 \mu \mathrm{IU} / \mathrm{ml})$ & $25.66 \mu \mathrm{IU} / \mathrm{dl}$ \\
\hline PTH $(15-65 \mathrm{pg} / \mathrm{ml})$ & $1.34 \mathrm{pg} / \mathrm{ml}$ \\
\hline Phosphorus $(2.6-5 \mathrm{mg} / \mathrm{dl})$ & $5.5 \mathrm{mg} / \mathrm{dl}$ \\
\hline Serum calcium $(8.6-10.3 \mathrm{mg} / \mathrm{dl})$ & $4.94 \mathrm{mg} / \mathrm{dl}$ \\
\hline
\end{tabular}

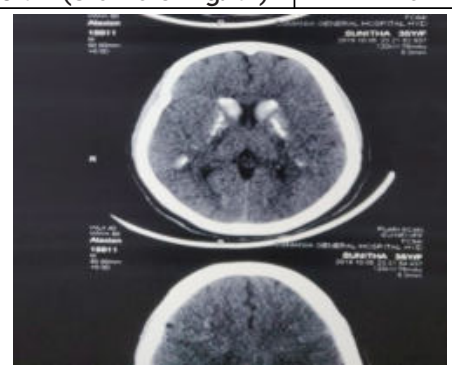

Fig.lnon Contrast Ct Of Brain Showing Calcification In Basal Ganglia And Centrum Semiovale.

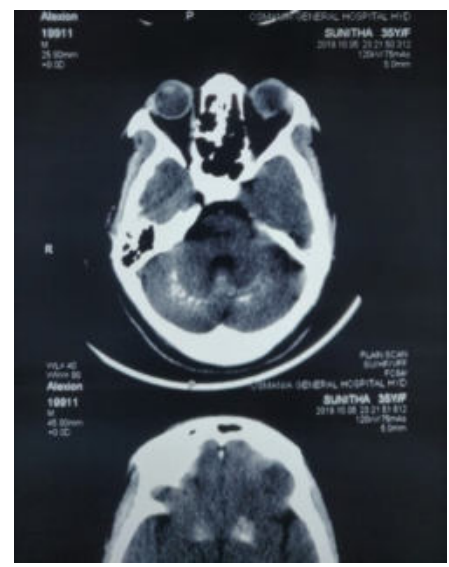

Fig.2 Non Contrast CT of brain showing calcification in cerebellar hemisphere. 


\section{DISCUSSION:}

The patient reported in the following case study had clinical ,biochemical and imaging features suggestive of Fahr's syndrome. A variety of neurological signs and symptoms are associated with Fahr's syndrome. In adults loss of consciousness and seizures have been reported with hypothyroid hypocalcaemia $(3,4)$.The main symptom noticed here is uncontrolled breakthrough seizures with complementary laboratory data showing hypocalcemia and hypoparathyroidism, computed tomography of brain showing pathognomic bilateral calcification of basal ganglia, centrum semi ovale and cerebellar nuclei.

The brain calcification can be seen in variety of conditions including endocrine disorders(idiopathic hypoparathyroidism, secondary hypoparathyroidism, pseudo hypoparathyroidism), Infectious diseases (Brucellosis, TORCH infections), Adult onset neurogenerative conditions and inherited syndromes (Cockayne Syndrome Type 1 ,Cockayne syndrome Type 2, Aicardi-Gouteres Syndrome ,Tuberous Sclerosis Complex, Coats disease)(1).The cause of calcification noted here is due to chronic hypocalcemia and hypoparathyroidism secondary to total thyroidectomy.

Postoperative hypoparathyroidism is a transitory condition in the majority of cases, and functional recovery occurs between ten days and six months after thyroidectomy; but some individuals have permanent disturbances of calcium metabolism, due to removal or devascularization of the glands $(5,6)$.Such cases may need a close monitoring and regular followup in order to prevent further complications. Individuals with Fahr's syndrome can evolve with nonspecific features for a long time, and they might be under risk of such complications(7).Mechanisms of disease involve changes in blood flow and cellular transport; precipitation and mineralization and persistent inflammatory processes, with brain lesions may show deposits of calcium; other minerals and lipids, and demyelinization(8).A constant check on such patients can be kept by period followup and repeated radiological and biochemical investigations.

\section{CONCLUSION:}

Through this case study, We recommend the follow up of blood calcium, phosphorus, PTH levels every 3 months during $1^{\text {st }}$ year after Thyroidectomy and every 6 months subsequently, for the long term follow up of post thyroidectomy patients along with routine CT scanning.

\section{REFERENCES:}

1. Shafaq S, Hafiz MA, Maheen A et al: Fahr's syndrome: Literature review of current evidence. Orphanet J Rare Dis, 2013;8:156

2. Lee, Yoo Jin et al. "A Case of Seizure Revealing Fahr's Syndrome with Primary Hypoparathyroidism." The American journal of case reports vol. 19 1430-1433. 1 Dec.2018, doi:10.12659/AJCR.913382.

3. Arias MJ, González MT, Escorial MC, Marañón CA: Intracranial calcifications in the differential diagnosis of epileptic disease]. Rev Clin Esp 1991, 189(9):425.

4. Arranz PM, Ergueta MP, González SE, Marañón CA: Fahr's disease and hypocalcemic syndromes. Presentation of a clinical case. In Anales de medicina interna. (Madrid, Spain; 1992:1992-495. http://www.ncbi.nlm.nih. gov/pubmed/1420763.

5. KHAN MI, WAGUENSPACK SG, HU MI. Medical management of postsurgical hypoparathyroidism. Endocr Pract 2011;17:18-25.

6. GULCELIK MA, KURU B, DINCER H, et al. Complications of completion versus total thyroidectomy. Asian Pac J Cancer Prev 2012; 13:5225-5228.

7. BRONCEL M, KORIZOG M, ZABIELSKA J, POLIWCZAK AR. Recurrent syncope and hypocalcaemic cardiomyopathy as manifestations of Fahr's syndrome. Arch Med Sci 2010;6:117-121.

8. GÜLSÜN M, BAYKIZ AF, KABATA $\square$ S, BELLI H. Fahr syndrome. Three cases presenting with psychiatric signs. Eur J Gen Med 2006;3:35-40. 